\title{
WestVirginiaUniversity
}

THE RESEARCH REPOSITORY @ WVU

Graduate Theses, Dissertations, and Problem Reports

2020

\section{Application of Flowing Material Balance in Unconventional Reservoirs}

\author{
Salem Alharbi \\ saalharbi@mix.wvu.edu
}

Follow this and additional works at: https://researchrepository.wvu.edu/etd

Part of the Petroleum Engineering Commons

\section{Recommended Citation}

Alharbi, Salem, "Application of Flowing Material Balance in Unconventional Reservoirs" (2020). Graduate Theses, Dissertations, and Problem Reports. 7881.

https://researchrepository.wvu.edu/etd/7881

This Problem/Project Report is protected by copyright and/or related rights. It has been brought to you by the The Research Repository @WVU with permission from the rights-holder(s). You are free to use this Problem/Project Report in any way that is permitted by the copyright and related rights legislation that applies to your use. For other uses you must obtain permission from the rights-holder(s) directly, unless additional rights are indicated by a Creative Commons license in the record and/ or on the work itself. This Problem/Project Report has been accepted for inclusion in WVU Graduate Theses, Dissertations, and Problem Reports collection by an authorized administrator of The Research Repository @ WVU. For more information, please contact researchrepository@mail.wvu.edu. 


\title{
Application of Flowing Material Balance in Unconventional Reservoirs
}

\author{
Salem Alharbi
}

Problem Report submitted to the Benjamin M. Statler College of Engineering and Mineral Resources at West Virginia University In partial fulfillment for the degree of Master of Science in Petroleum and Natural Gas Engineering

\author{
Kashy Aminian, $\mathrm{PhD}$, Chair \\ Samuel Ameri, $\mathrm{PhD}$ \\ Ming Gu, $\mathrm{PhD}$
}

Department of Petroleum and Natural Gas Engineering, Morgantown, West Virginia 2020

Keywords: Flowing Material Balance, Gas in Place, Unconventional Reservoir Copyright: 2020 Salem Alharbi 


\section{Abstract \\ Application of Flowing Material Balance in Unconventional Reservoirs}

\section{Salem Alharbi}

The application of the horizontal drilling and hydraulic fracturing to unconventional reservoirs, such as Marcellus Shale, has resulted in a significant increase in gas production in the United States. The estimation of the original hydrocarbons in place is an essential element for evaluating the economic success of any reservoir. There are a number of techniques available for estimating the original hydrocarbon in place such as decline curve analysis, volumetric method, and the material balance equation. Flowing Material Balance (FMB) is a more advanced techniques which has become popular in recent years because it does not require static (shut-in) pressure data which is required by the traditional material balance equation application. This is particularly useful for the shale reservoirs where shut-in pressure data are rarely available. However, the application FMB in shale reservoirs is challenging because of the presence of the adsorbed gas due to high organic content and the long time that is required to establish boundary dominated flow (BDF) due to extremely low permeability.

In this study, a reservoir model was developed based on the Marcellus Shale reservoir properties obtained from the analysis of the available data from well MIP-6H in Morgantown, WV. The simulated pressure and production data were then utilized to estimate the original gas in place by the application of the FMB technique. Several modifications to FMB were also investigated to account for the adsorbed gas and the long BDF time. 


\section{Acknowledgement}

I want to express my gratitude and appreciation to my research advisor Dr. Kashy Aminian for his support and motivation during my graduate program. With his help and guidance, I was able to complete my research.

Also, I would like to thank professor. Sam, for his support and motivation through my graduate program.

Finally, I want to thank my family and friends for their prayer and support, which led me to achieve my goal and complete my master's degree. 


\section{Contents}

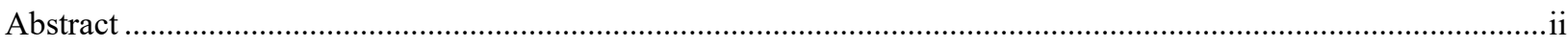

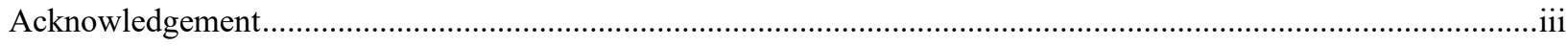

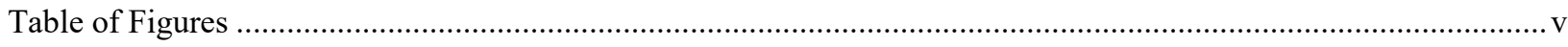

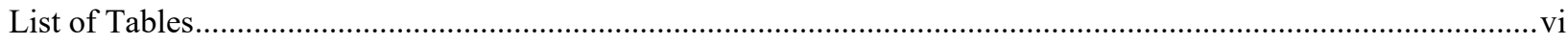

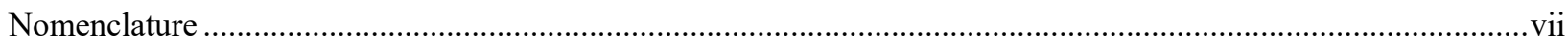

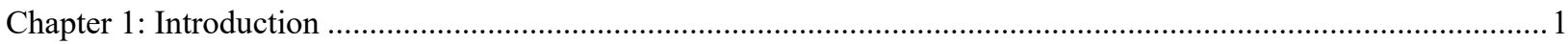

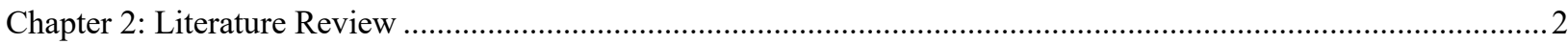

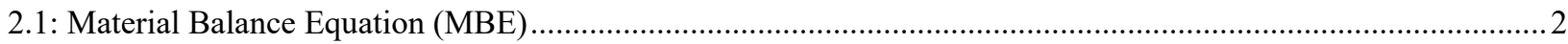

2.2: Flowing Material Balance for Gas Reservoir ..................................................................................

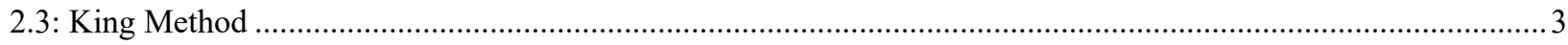

2.4: Clarkson and McGovern Method .......................................................................................................

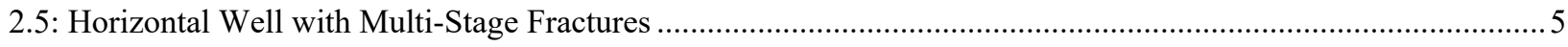

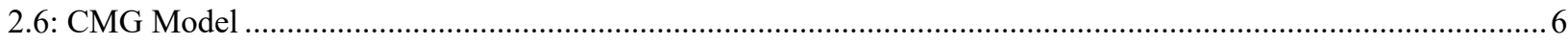

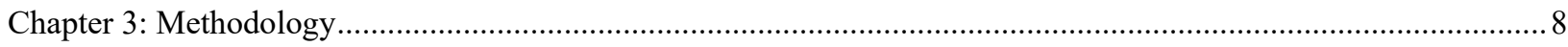

3.1. Simulated Pressure and Production Data for a Marcellus Shale Horizontal Well ............................................ 8

3.2. Gas in Place Estimation by the Conventional FMB ...................................................................... 10

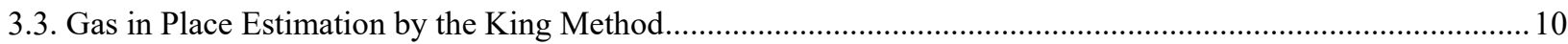

3.4. Gas in Place Estimation by the Clarkson-McGovern Method .................................................................. 11

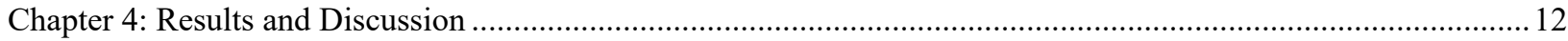

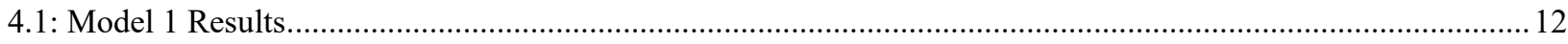

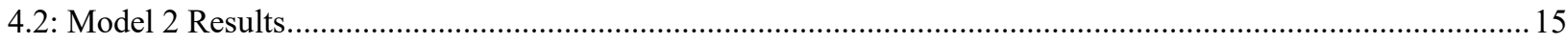

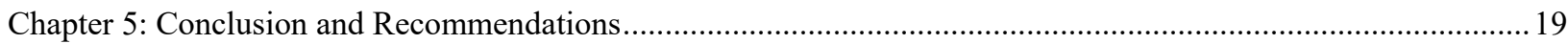

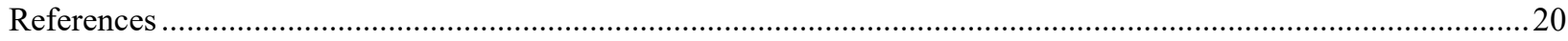




\section{Table of Figures}

Figure 1: Flow Regimes for Horizontal Well with Multi-Stage Fractures ....................................... 6

Figure 2: Well bottomhole Pressure Profile for Model 1 ......................................................... 12

Figure 3 : Conventional Flowing Material Balance Plot for Model 1 ............................................. 13

Figure 4: King Flowing Material Balance Plot for Model 1 ................................................... 14

Figure 5: Clarkson-McGovern Flowing Material Balance Plot for Model 1 ................................... 14

Figure 6: Well bottomhole Pressure Profile for Model 2 ........................................................ 15

Figure 7: Conventional Flowing Material Balance Plot for Model 2 .......................................... 16

Figure 8: King Flowing Material Balance Plot for Model 2 .................................................. 17

Figure 9: Clarkson-McGovern Flowing Material Balance Plot for Model 2 ................................. 17 


\section{List of Tables}

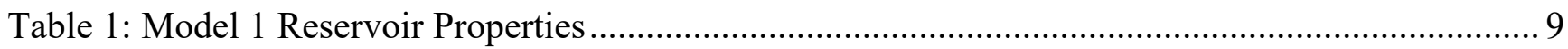

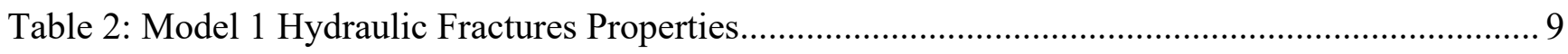

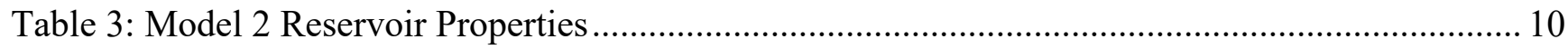

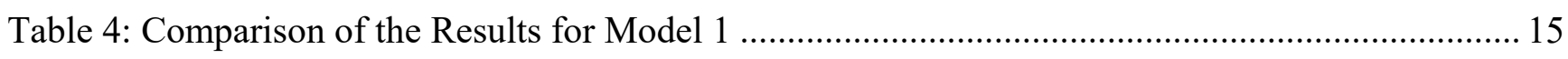

Table 5: Comparison of the Results for Model 2 ............................................................................. 18 


\section{Nomenclature}

$B_{g}=$ gas formation volume factor,$r c f / s c f$

$B_{g i}=g$ as formation volume factor at initial pressure,$r c f / s c f$

$B_{w}=$ water formation volume factor,$r c f / s c f$

$b_{p s s}=$ Reservoir constant (pseudo steady state)

$c_{f}=$ formation compressiblity, $1 / p s i$

$c_{g}=$ gas compressiblity, $1 / p$ si

$c_{g i}=$ gas compressiblity at initial pressure, $1 / p s i$

$c_{t}=$ total compressiblity, $1 / p s i$

$c_{t i}=$ total compressiblity at initial pressure, $1 / p s i$

$c_{w}=$ water compressiblity, $1 / p s i$

$G=$ initial gas in place,$M M C F$

$G_{p}=$ cumulative gas production, $M M C F$

$h=$ formation thickness, $\mathrm{ft}$

$k=$ permeability, $m d$

$m\left(p_{i}\right)=$ pseudo pressure at initial pressure,$p s i^{2} / c p$

$m\left(p_{w f}\right)=$ well bottomohole flowing pseudo pressure,$p s i^{2} / c p$

$m(\bar{p})=$ average reservoir pseudo pressure, $\mathrm{psi}^{2} / \mathrm{cp}$

$m(p)=$ pseudo pressure,$p s i^{2} / c p$

$\bar{p}=$ average pressure, $p$ sia

$p=$ pressure, $p$ sia

$p_{L}=$ Langmuir pressure,$p s i a$

$p_{i}=$ initial reservoir pressure, psia

$p_{w f}=$ well bottomhole pressure, $p$ sia

$q_{g}=$ gas flow rate,$M M C F D$

$r_{e}=$ drainage radius,$f t$

$r_{w}=$ wellbore radius,$f t$

$r_{w a}=$ apparent wellbore radius $, f t, r_{w a}=r_{w} e^{-s}$ 


$$
\begin{aligned}
& S_{w}=\text { water saturation, dimensionless } \\
& S_{w i}=\text { irreducible water saturation, dimensionless } \\
& T=\text { Temperature, }{ }^{\circ} R \\
& t_{c a}=\text { adjusted material balance pseudo time, days } \\
& u_{g}=\text { gas viscosity }, c p \\
& u_{g i}=\text { gas viscosity at initial pressure }, c p \\
& V_{L}=\text { Langmuir volume }, \text { scf } / \text { ton } \\
& W_{e}=\text { water influx }, r b \\
& W_{p}=\text { water production, } S T B \\
& z=\text { deviation factor }, \text { dimensionless } \\
& z^{*}=\text { deviation factor for unconventional reservoir, dimensionless } \\
& z_{i}=\text { deviation factor at initial pressure, dimensionless } \\
& \rho_{b}=\text { bulk density, scf /ton } \\
& \varnothing=\text { porosity } \text {, fraction }
\end{aligned}
$$




\section{Chapter 1: Introduction}

The estimation of the hydrocarbons initially in the reservoir (hydrocarbons in place) is a crucial step in the evaluation of the profitability of the reservoir. Hydrocarbons in place can be estimated by three methods: Volumetric, Production Decline, and Material Balance Equation (MBE).

MBE analysis has been applied to the oil and gas reservoir for many decades and has gained widespread acceptance due to its simplicity and accuracy in estimation of the hydrocarbons in place and reserves. The traditional material balance equation relates the cumulative hydrocarbon production to the average reservoir pressure which is obtained by shutting-in the reservoir. MBE is based on the assumption that the reservoir has been producing under pseudo-steady state or boundary dominated flow (BDF) conditions. Mattar and McNeil (1998) developed the concept of the Flowing Material Balance (FMB) which is a recent approach for estimation of the hydrocarbons in place and reserves by MBE. The key advantage of FMB is that it does not require shut-in reservoir pressures.

FMB has been successfully applied in different type of reservoirs, however, its applicability to the unconventional shale gas reservoirs is uncertain. The presence of the adsorbed gas, due to high organic content of the shale, precludes the direct application of FMB to unconventional reservoirs (Guofeng et al, 2020). Several modifications to MBE have been introduced by (King 1993; Clarkson and McGovern 2001; Ahmed et al. 2006) to account for the adsorbed gas volume in unconventional reservoirs.

The long time required for establishing BDF in unconventional reservoirs, due to ultra-low permeability, makes the application FMB to the shale reservoirs challenging. It should however be noted that most shale reservoir are developed by horizontal well coupled with multi-stage hydraulic fracturing to create a stimulated volume around the horizontal well. The time required for establishing BDF in the stimulated reservoir volume could significantly shorter. This provides an opportunity for the application of FMB for estimation of the gas in place for shale reservoirs. 


\section{Chapter 2: Literature Review}

\section{1: Material Balance Equation (MBE)}

Static material balance equation (MBE) is a mathematical expression of the conservation of mass in a reservoir. MBE can be used to estimate the original hydrocarbon in place. However, this methodology requires the well to be shut-in for a while until the reservoir pressure stabilizes in order to estimate the average reservoir pressure. The MBE for a gas reservoir is expressed as:

$$
\frac{p}{z}=\frac{p_{i}}{z_{i}}\left(1-\frac{G_{p}}{G}\right)
$$

\section{2: Flowing Material Balance for Gas Reservoir}

The conventional material balance cannot be applied to low permeability reservoirs due to the long shut-in time required to obtain the average reservoir pressure. To overcome this problem, Mattar and McNeil (1998) and Mattar and Anderson (2005) proposed the "Dynamic" or Flowing Material Balance (FMB) Equation. FMB equation can be used to determine the average reservoir pressure based on the flowing pressures, production rates, and the time. In this method, production rates can be either constant or variable.

The dependency of gas properties on the pressure and time must be considered in FMB approach for gas reservoirs. To account for dependency of the gas properties on the pressure, the real gas potential or pseudopressure (Al-Hussainy et al.1966) defined by the following equation can be utilized:

$$
m(p)=\int_{0}^{p}\left(\frac{2 p}{\mu_{g z}}\right) d p
$$

To account for the changes in the gas properties with time, the material balance pseudo-time (Mattar and Anderson 2005) defined by the following equation can be utilized:

$$
t_{C a}=\frac{\left(\mu_{g} C_{t}\right)_{i}}{q_{g}} \int_{0}^{t} \frac{q_{g}}{\bar{\mu}_{g} \bar{C}_{t}} d t
$$

Mattar and Anderson (2005) modified the pseudo-steady gas flow equation as follows:

$$
m\left(p_{i}\right)-m\left(p_{w f}\right)=\frac{2 p_{i} q}{\left(\mu Z c_{g}\right)_{i} G_{i}} t_{c a}+\frac{1.417 \times 10^{6} T q}{k h}\left(\ln \left(\frac{r_{e}}{r_{w a}}\right)-\frac{3}{4}\right)
$$


And defined $b_{a, p s s}$ as:

$$
b_{a, p s s}=\frac{1.417 \times 10^{6} T}{k h}\left(\ln \left(\frac{r_{e}}{r_{w a}}\right)-\frac{3}{4}\right)
$$

Therefore equation 2.2.3 becomes:

$$
\frac{m\left(p_{i}\right)-m\left(p_{w f}\right)}{q}=\frac{2 p_{i}}{\left(\mu Z c_{g}\right)_{i} G_{i}} t_{c a}+b_{a, p s s}
$$

According to equation 2.2.5, a plot of $\frac{m\left(p_{i}\right)-m\left(p_{w f}\right)}{q}$ against $t_{c a}$ will yield a straight-line where:

$$
\begin{aligned}
& \text { Slope }=\frac{2 p_{i}}{\left(u z c_{t}\right)_{i} * G_{i}} \\
& \text { Intercept }=b_{a, p s s}=\frac{1.417 \times 10^{6} T}{k h}\left(\ln \left(\frac{r_{e}}{r_{w a}}\right)-\frac{3}{4}\right)
\end{aligned}
$$

The following steps describe how the conventional flowing material balance can be applied:

1. Convert $p_{i}$ and $p_{w f}$ to pseudopressure

2. Assume a value for the initial gas in place value $(G)$.

3. Calculate $\frac{p}{z}$ for each cumulative gas production using Equation 2.1.1

4. Determine the average reservoir pressure, $p$, corresponding to $\frac{p}{z}$ value.

5. Determine gas viscosity and compressibility at the average reservoir pressure.

6. Determine the material balance pseudo-time using Equation 2.2.2.

7. Plot $\frac{m\left(p_{i}\right)-m\left(p_{w f}\right)}{q}$ against $t_{c a}$ and draw a straight line through the points.

8. The gas in place can be calculated from Equation 2.2.6

9. Repeat steps 4-8 until the assumed and the calculated values of the initial gas in place converge.

\section{3: King Method}

Gregory King (1993) developed a new MBE to account for the presence of adsorbed gas in shale and coalbed methane reservoirs. This MBE is given by equation 2.3.1:

$$
\frac{p}{z^{*}}=\frac{p_{i}}{z_{i}^{*}}\left(1-\frac{G_{p}}{G}\right)
$$

Where:

$$
z^{*}=\frac{z}{\left(1-c_{f}\right) *\left(p_{i}-p\right) *\left(1-S_{w}\right)+\frac{\rho_{b}{ }^{* B} g}{\theta} *\left(\frac{V_{L^{* p}}}{P_{L^{+}}}\right)}
$$


and

$$
S_{w}=\frac{S_{w i}\left(1+c_{w}\left(p_{i}-p\right)\right)+\frac{W_{e}-B_{w} W_{p}}{\theta A h}}{1-c_{f}\left(p_{i}-p\right)}
$$

For shale gas reservoir, water production and influx can be assumed zero which will lead to the following equation:

$$
Z^{*}=\frac{z}{S_{g i}-\left(c_{f}+c_{w} S_{w i}\right) *\left(p_{i}-p\right)+\frac{\rho_{b^{* B}} g}{\theta} *\left(\frac{V_{L^{*}} p}{P_{L}+p}\right)}
$$

King's material balance equation can then be used with the FMB approach by replacing use Equation 2.1.1 with Equation 2.3.1, where $z^{*}$ can be determined by equation 2.3.4..

\section{4: Clarkson and McGovern Method}

Clarkson and McGovern (2001) introduced a new MBE that accounts for gas adsorption, but ignored the water and formation compressibility's. The Clarkson-McGovern equation is expressed as follow,

$$
\frac{p}{p+p_{L}}+\frac{32037 \varnothing\left(1-S_{w}\right)}{V_{L} B_{g} \rho_{c}}=\frac{-0.7355}{V_{L} A h \rho_{c}} G_{p}+\left[\frac{p_{i}}{p+p_{L}}+\frac{32037 \emptyset\left(1-S_{w i}\right)}{V_{L} B g i \rho_{c}}\right]
$$

Water production is incorporated as follows:

$$
S_{w}=S_{w i}-\frac{B_{w} W_{p}}{\emptyset A h}
$$

If the water production is ignored, the equation becomes:

$$
\frac{p}{p+p_{L}}+\frac{32037 \varnothing\left(1-S_{w i}\right)}{V_{L} B_{g} \rho_{c}}=\frac{-0.7355}{V_{L} A h \rho_{c}} G_{p}+\left[\frac{p_{i}}{p_{i}+p_{L}}+\frac{32037 \varnothing\left(1-S_{w i}\right)}{V_{L} B_{g i} \rho_{c}}\right]
$$

Clarkson-McGovern's material balance equation can then be used with FMB approach. The same procedure for FMB method can be followed except for the average reservoir pressure calculations in step 4. The average reservoir can be obtained by rearranging equation 2.4.3 as:

$$
\alpha=\frac{-0.7355}{V_{L} A h \rho_{c}} G_{p}+\beta
$$

Where: 


$$
\begin{gathered}
\alpha=\frac{p}{p+p_{L}}+\frac{32037 \emptyset\left(1-S_{w i}\right)}{V_{L} B_{g} \rho_{c}} \\
\beta=\frac{p_{i}}{p_{i}+p_{L}}+\frac{32037 \emptyset\left(1-S_{w i}\right)}{V_{L} B_{g i} \rho_{c}}
\end{gathered}
$$

Note that when $\alpha=0$

$$
G_{p}=G=\frac{\beta \times\left(V_{L} A h \rho_{c}\right)}{0.7355}
$$

And

$$
A h=\frac{0.7355 G}{\beta \times V_{L} \rho_{c}}
$$

The following steps describe how the average pressure can be calculated:

1. Calculate $\beta$ using equation 2.4.6.

2. Determine Ah using equation 2.4.8.

3. Calculate $\alpha$ for each cumulative production using equation 2.4.4.

4. Determine the corresponding average pressure for each $\alpha$ using equation 2.4.5.

\section{5: Horizontal Well with Multi-Stage Fractures}

In the last few years, many horizontal wells have been drilled in north America. Horizontal wells with multiple hydraulic fractures are the key technology to achieve economic production from shale gas reservoirs. Furthermore, the application of the hydraulic fracturing to create a high conductivity pathway in shale gas reservoirs has led to a dramatic increase in economically recoverable hydrocarbons from ultra-low permeability shale reservoirs. A hydraulic fracture treatment is performed by pumping fluid into the wellbore to increase the downhole pressure to a value greater than the fracture pressure (closure pressure) of the formation rock. This applied pressure causes the formation to crack, allowing the injected fluid to enter and extend the crack farther into the formation. Then a solid proppant, such as sand, is pumped into the fractures to prevent the cracks from closing after the injection is ceased. The propped hydraulic fracture becomes a high permeability conduit through which the gas can flow to the well. Moreover, Figure 1 illustrates the flow regimes in a horizontal well which includes formation 
linear flow, fracture interference, linear flow in unstimulated matrix, and boundary dominated flow. There is a possibility that the well might goes through two boundary dominated flow periods. The first straight line that resemble the first boundary dominated flow is related to the stimulated reservoir volume (SRV) that is caused by the hydraulic fractures. Reserve estimation in this flow will not lead to the total gas in place, however it will result in the stimulated reservoir volume (SRV) which is less than the original gas in place.

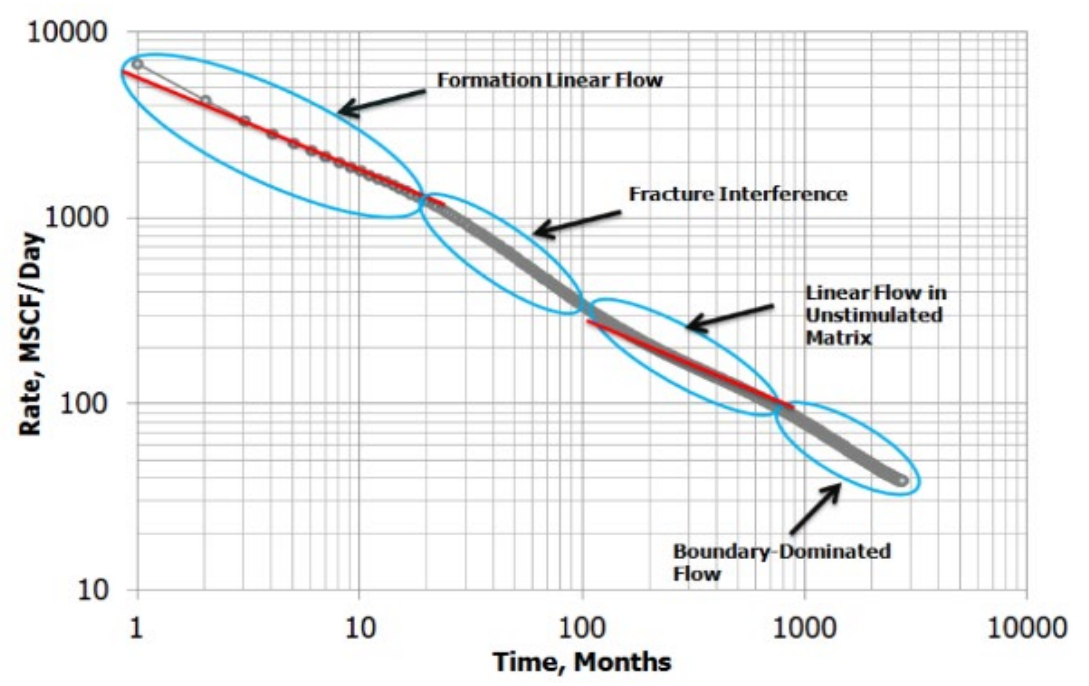

Figure 1: Flow Regimes for Horizontal Well with Multi-Stage Fractures

\section{6: CMG Model}

The CMG software is used to build a reservoir model for an oil or a gas reservoir. The CMG model simulate the behavior of the reservoir based on the input that is provided such as reservoir parameters, fluid types, initial reservoir parameters, hydraulic fractures parameters, and Langmuir constants for unconventional reservoir. In addition, the CMG is a powerful tool that can provide the reservoir engineer with several information such as the reservoir performance and the estimation of hydrocarbon in place. A reservoir simulation model (CMG-GEM, 2019) was used to develop the base models for the horizontal well in this study. A logarithmically-spaced, locally refined, dual-permeability (LS-LR-DK) reservoir model was adopted to effectively simulate hydraulic fracture and natural fracture 
behavior. The dual permeability model was selected to incorporate the naturally fractured nature of shales, and the logarithmic refinement was required to capture the transient effects around the hydraulic fracture. Evenly spaced gridding would allow for the fine gridding required around the fracture, but it would not create unnecessary grid refinement far away from the fracture. The dual-permeability model accounts for the flow that can occur in the natural fractures, in the matrix, and from the natural fracture to matrix. 


\section{Chapter 3: Methodology}

The objective of this study was to investigate the applicability of the FMB method to Marcellus Shale gas reservoir. The following steps were taken during this study to achieve the objective.

1. Generate simulated pressure and production data for a Marcellus Shale Horizontal Well

2. Estimate the gas in place by applying King method to the simulated production and pressure data.

3. Estimate the gas in place by applying Clarkson-McGovern method to the simulated production and pressure data.

4. Comparison of the Results

These steps are explained below.

\subsection{Simulated Pressure and Production Data for a Marcellus Shale Horizontal Well}

Two reservoir models were developed to simulate the production and pressure data for this study. The reservoir model which has been previously developed for well MIP-6H at MSEEL site in Morgantown with CMG-GEM simulation software (El Sgher el. 2019), was used to build the models for this study.

\subsection{1: Model 1}

Tables 1 and 2 summarize the reservoir parameters that were used to build model 1 which is an ultra-low permeability shale reservoir that is stimulated with hydraulic fractures in multiple stages. The well flowing pressures were simulated using a constant rate of 300000 SCFD for ten years. The simulated well bottomhole pressures were then utilized for the flowing material balance analysis. 
Table 1: Model 1 Reservoir Properties

\begin{tabular}{|l|l|l|}
\hline Reservoir parameters & Value & $\mathrm{Unit}$ \\
\hline Model Dimensions (i*j*k) & $4000 * 1000 * 90$ & $\mathrm{ft}$ \\
\hline Initial Reservoir Pressure & 4800 & $\mathrm{psia}$ \\
\hline $\begin{array}{l}\text { Initial Reservoir } \\
\text { Temperature }\end{array}$ & 180 & \\
\hline Gas Gravity & 0.55 & dimensionless \\
\hline Matrix Porosity & 0.035 & dimensionless \\
\hline Fracture Porosity & 0.0001 & dimensionless \\
\hline Matrix Permeability(i,j,k) & $0.0004,0.0004,0.00004$ & md \\
\hline Fracture Permeability (i,j,k) & $0.001,0.001,0,0001$ & md \\
\hline Water Saturation & 0.15 & dimensionless \\
\hline Rock Density & 120 & $\mathrm{lb} / \mathrm{ft}^{3}$ \\
\hline Langmuir Pressure & 240 & $\mathrm{psi}$ \\
\hline Langmuir Volume & 0.032 & $\mathrm{gmol} / \mathrm{lb}$ \\
\hline
\end{tabular}

Table 2: Model 1 Hydraulic Fractures Properties

Fracture Properties

\begin{tabular}{|l|c|c|}
\hline Fracture Half-length, $\mathbf{X}_{\mathbf{f}}$ & 300 & $\mathrm{ft}$. \\
\hline Fracture Conductivity $\mathbf{K}_{\mathbf{f}}{ }^{*} \mathbf{w}_{\mathbf{f}}$ & 100 & md-ft. \\
\hline Number of Hydraulic Fracture & 11 & dimensionless \\
\hline Stage Spacing & 300 & $\mathrm{ft}$. \\
\hline
\end{tabular}

\subsection{2: Model 2}

Table 3 summarizes the reservoir parameters that were used to build model 2 which does not include hydraulic fractured and its permeability is higher. The model was simulated under a constant rate condition of 300000 SCFD to obtain the well bottomhole pressure behavior for the well. 
Table 3: Model 2 Reservoir Properties

\begin{tabular}{|l|l|l|}
\hline Reservoir parameters & Value & $\mathrm{ft}$ \\
\hline Model Dimensions $\left(\mathbf{i}^{*} \mathbf{j} * \mathbf{k}\right)$ & $4000^{*} 1000^{*} 90$ & $\mathrm{psia}$ \\
\hline Initial Reservoir Pressure & 4800 & ${ }^{\circ} \mathrm{F}$ \\
\hline $\begin{array}{l}\text { Initial Reservoir } \\
\text { Temperature }\end{array}$ & 180 & \\
\hline Gas Gravity & 0.55 & dimensionless \\
\hline Matrix Porosity & 0.035 & dimensionless \\
\hline Fracture Porosity & 0.0001 & dimensionless \\
\hline Matrix Permeability(i,j,k) & $0.1,0.1,0.01$ & $\mathrm{md}$ \\
\hline Fracture Permeability $(\mathbf{i}, \mathbf{j}, \mathbf{k})$ & $0.001,0.001,0,0001$ & $\mathrm{md}$ \\
\hline Water Saturation & 0.15 & $\mathrm{dimensionless}$ \\
\hline Rock Density & 120 & $\mathrm{lb} / \mathrm{ft}^{3}$ \\
\hline Langmuir Pressure & 240 & $\mathrm{psi}$ \\
\hline Langmuir Volume & 0.032 & $\mathrm{gmol} / \mathrm{lb}$ \\
\hline
\end{tabular}

\subsection{Gas in Place Estimation by the Conventional FMB}

A spreadsheet model was developed to estimate the gas in place following the steps outlined in Chapter 2 for the conventional FMB method. The spreadsheet model included several routines to determine gas deviation factor, gas viscosity, gas compressibility, pseudopressure, and the material balance pseudo-time based on the gas gravity, reservoir temperature, and the average reservoir pressure.

\subsection{Gas in Place Estimation by the King Method}

A spreadsheet model was developed to estimate the gas in place following the steps outlined in Chapter 2 for the King's method. The spreadsheet model included several routines to determine gas deviation factor as described by Equation 2.3.4, gas viscosity, gas compressibility, pseudopressure, and the material balance pseudo-time based on the gas gravity, reservoir temperature, and the average reservoir pressure. 


\subsection{Gas in Place Estimation by the Clarkson-McGovern Method}

A spreadsheet model was developed to estimate the gas in place following the steps outlined in Chapter 2 for the Clarkson-McGovern method. The spreadsheet model included several routines to determine gas deviation factor, gas viscosity, gas compressibility, pseudopressure, and the material balance pseudo-time based on the gas gravity, reservoir temperature, and the average reservoir pressure. 


\section{Chapter 4: Results and Discussion}

\section{1: Model 1 Results}

Figure 2 illustrates the well bottomhole pressure profile for Model 1.

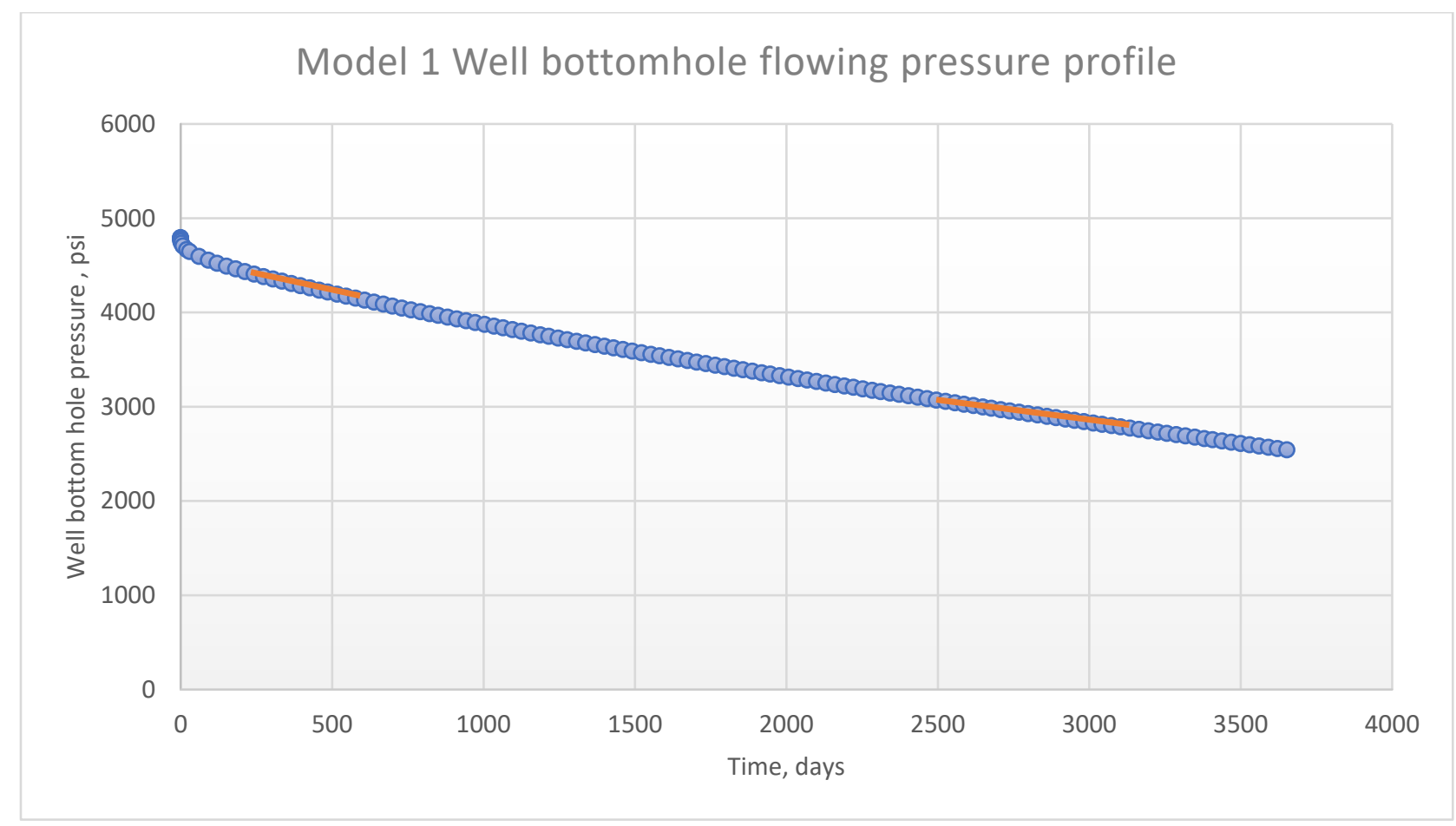

Figure 2: Well bottomhole Pressure Profile for Model 1

Based on figure 2, The early BDF period for all methods appears to be in the range of 300-600 days in real time. Moreover, the late BDF period of conventional method appears to be from 2800-3100 days in real time which correspond to 2270-2461 in pseudo time. The late BDF period of King's method appears to be from 2500-2600 days in real time which correspond to 1911-2003 in pseudo time. The late BDF period of Clarkson-McGovern method appears to be from 2500-2700 days in real time which correspond to $2015-2150$ in pseudo time.

Figure 3 illustrates that the FMB plot for Model 1. As it can be observed, two periods of the BDF(straight-line trends) appear to be present. The gas in place was calculated based on the both slopes 
of the early BDF and the late BDF. The estimated of gas in place based on the late BDF turned out to be $4798 \mathrm{MMCF}$. The estimated of gas in place based on the early BDF line was determined to be 3181 MMCF.

Figure 4 illustrates FMB plot based on the King's method for Model 1. Again, two periods of the BDF appear to be present. The late BDF resulted in a gas in place of $4782 \mathrm{MMCF}$ and the early BDF resulted in a gas in place of $3491 \mathrm{MMCF}$.

Figure 5 illustrates FMB plot based on the Clarkson-McGovern method for Model 1. Again, two periods of the BDF appear to be present. The late BDF resulted in a gas in place of $4431 \mathrm{MMCF}$ and the early BDF resulted in a gas in place of $3091 \mathrm{MMCF}$. Table 4 summarizes the Model 1 results for each case for comparison.

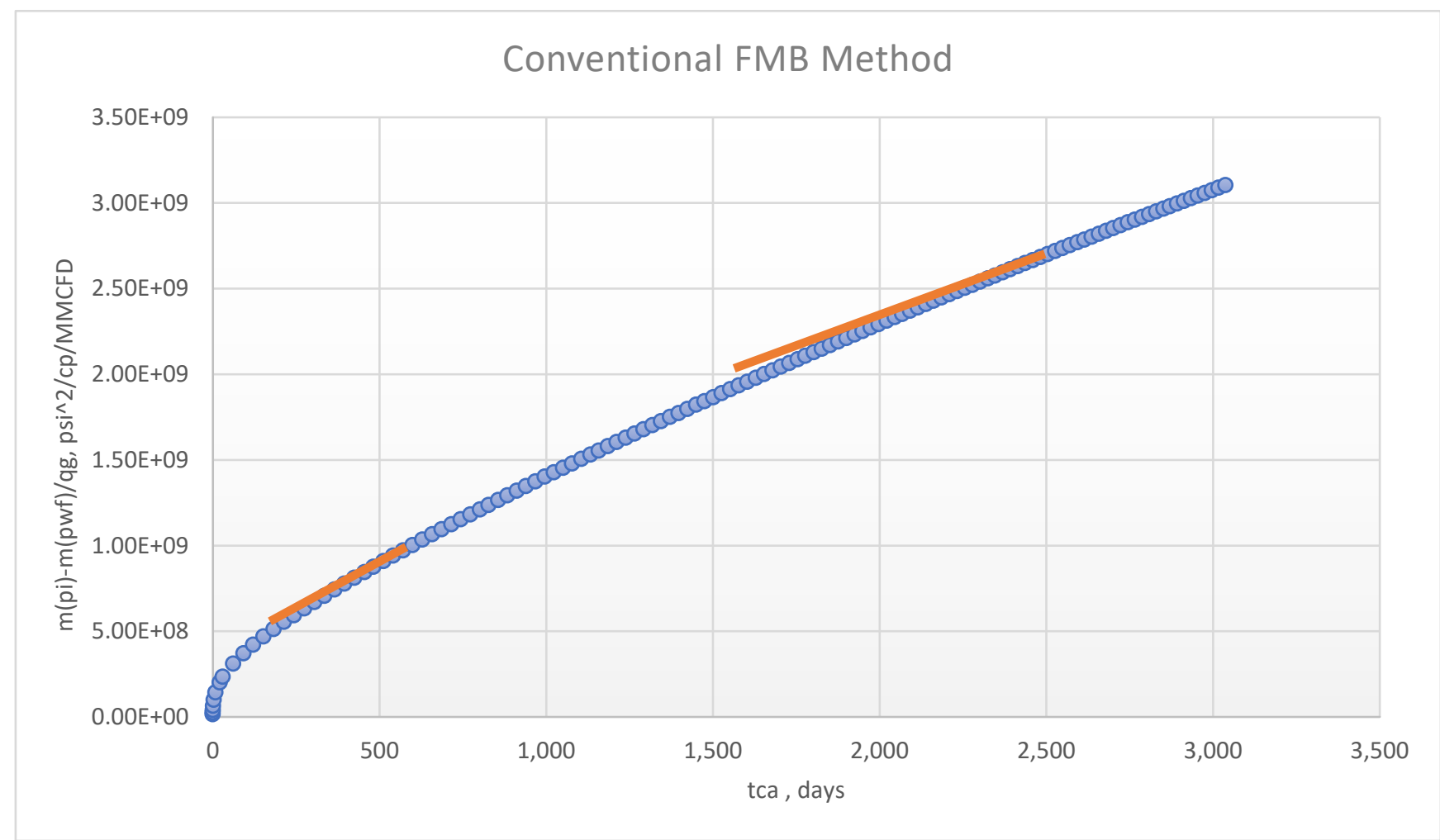

Figure 3 : Conventional Flowing Material Balance Plot for Model 1 


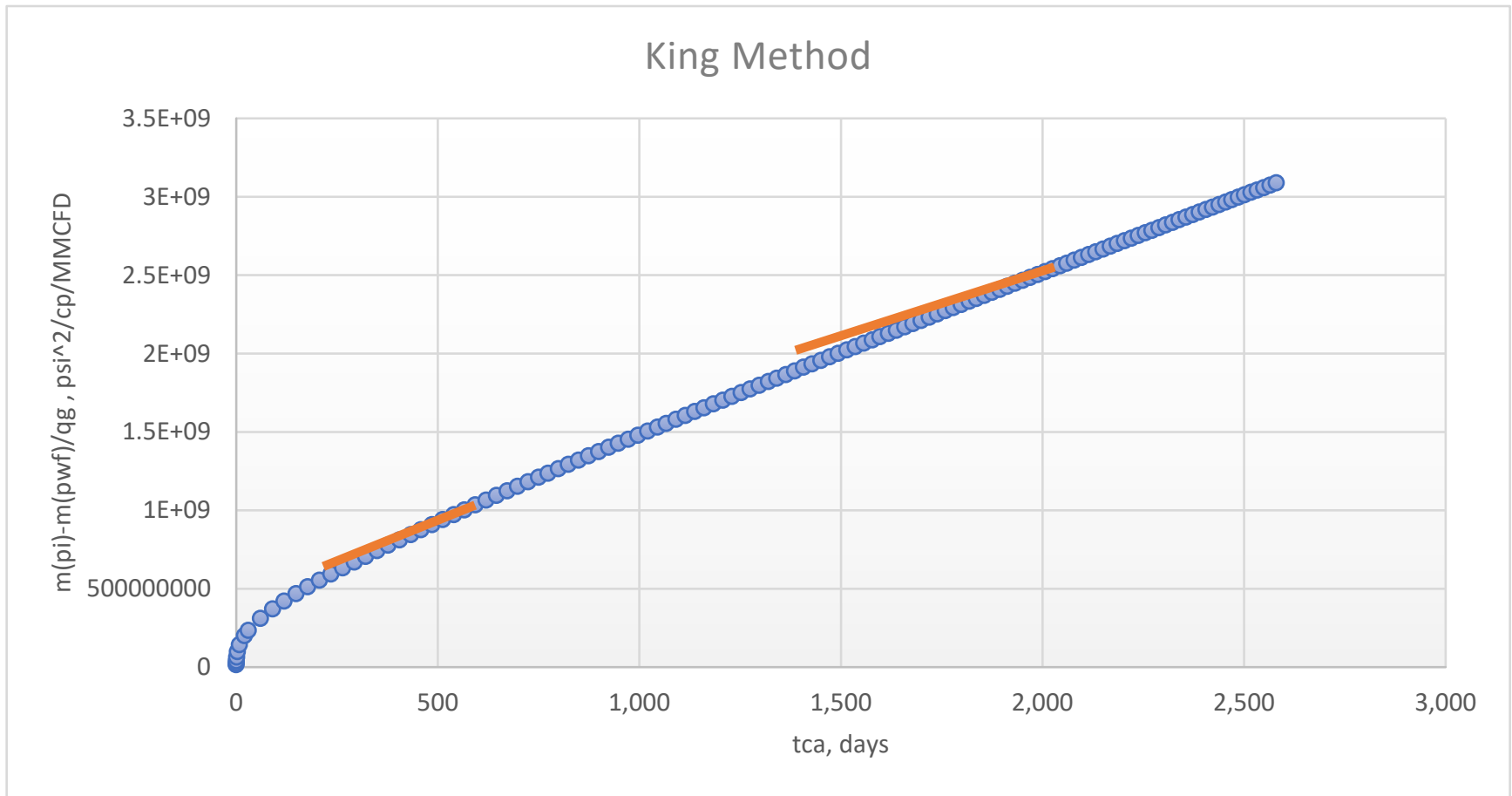

Figure 4: King Flowing Material Balance Plot for Model 1

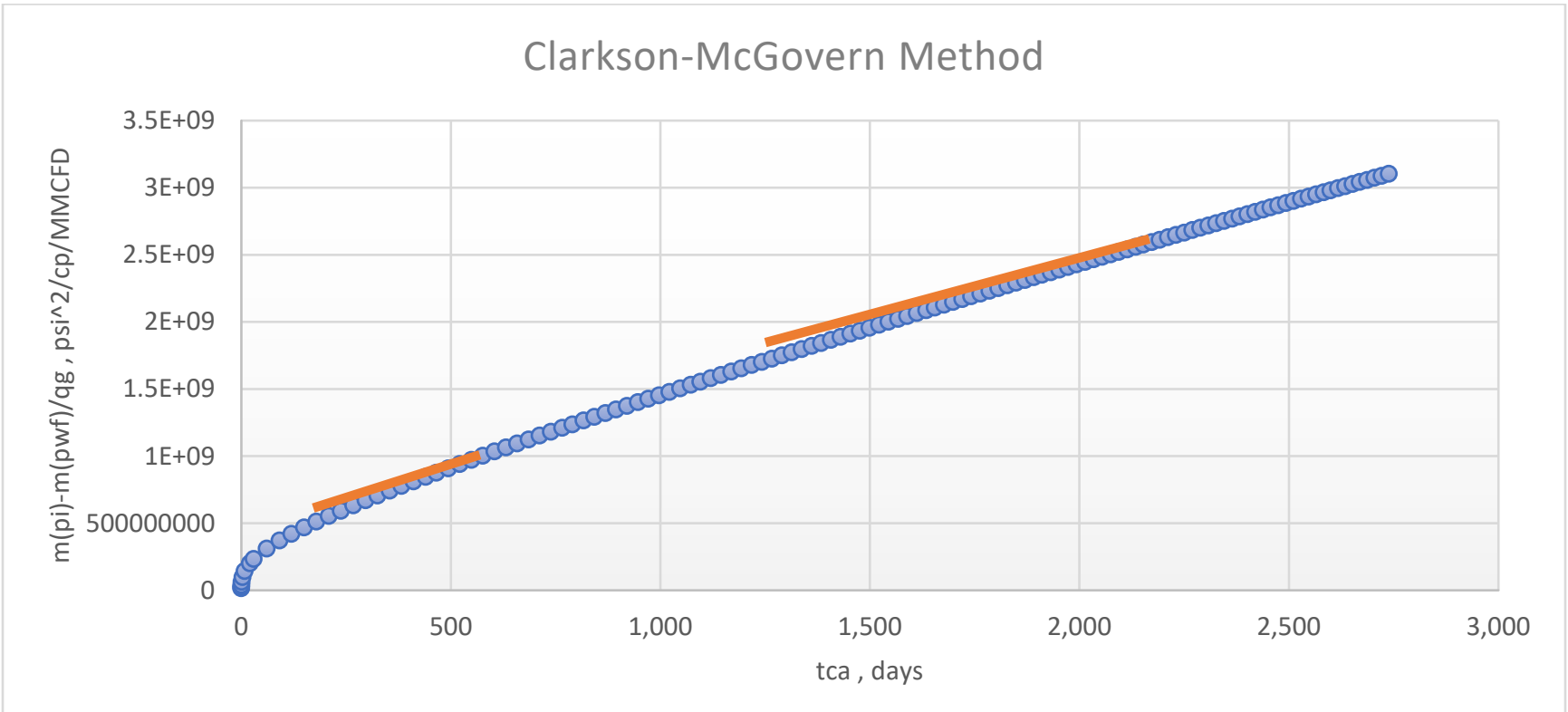

Figure 5: Clarkson-McGovern Flowing Material Balance Plot for Model 1 
Table 4: Comparison of the Results for Model 1

\begin{tabular}{|l|c|c|}
\hline \multicolumn{1}{|c|}{$\begin{array}{c}\text { Gas in Place, Early BDF } \\
\text { MMCF }\end{array}$} & \begin{tabular}{c} 
Gas in Place, Late BDF ,MMCF \\
\hline Method
\end{tabular} \\
\hline CMG Model & 2006 & 4304 \\
\hline Conventional FMB & 3181 & 4798 \\
\hline King Method & 3491 & 4782 \\
\hline Clarkson-McGovern Method & 3091 & 4431 \\
\hline
\end{tabular}

\section{2: Model 2 Results}

Figure 6 illustrates the well bottomhole pressure profile for Model 2.

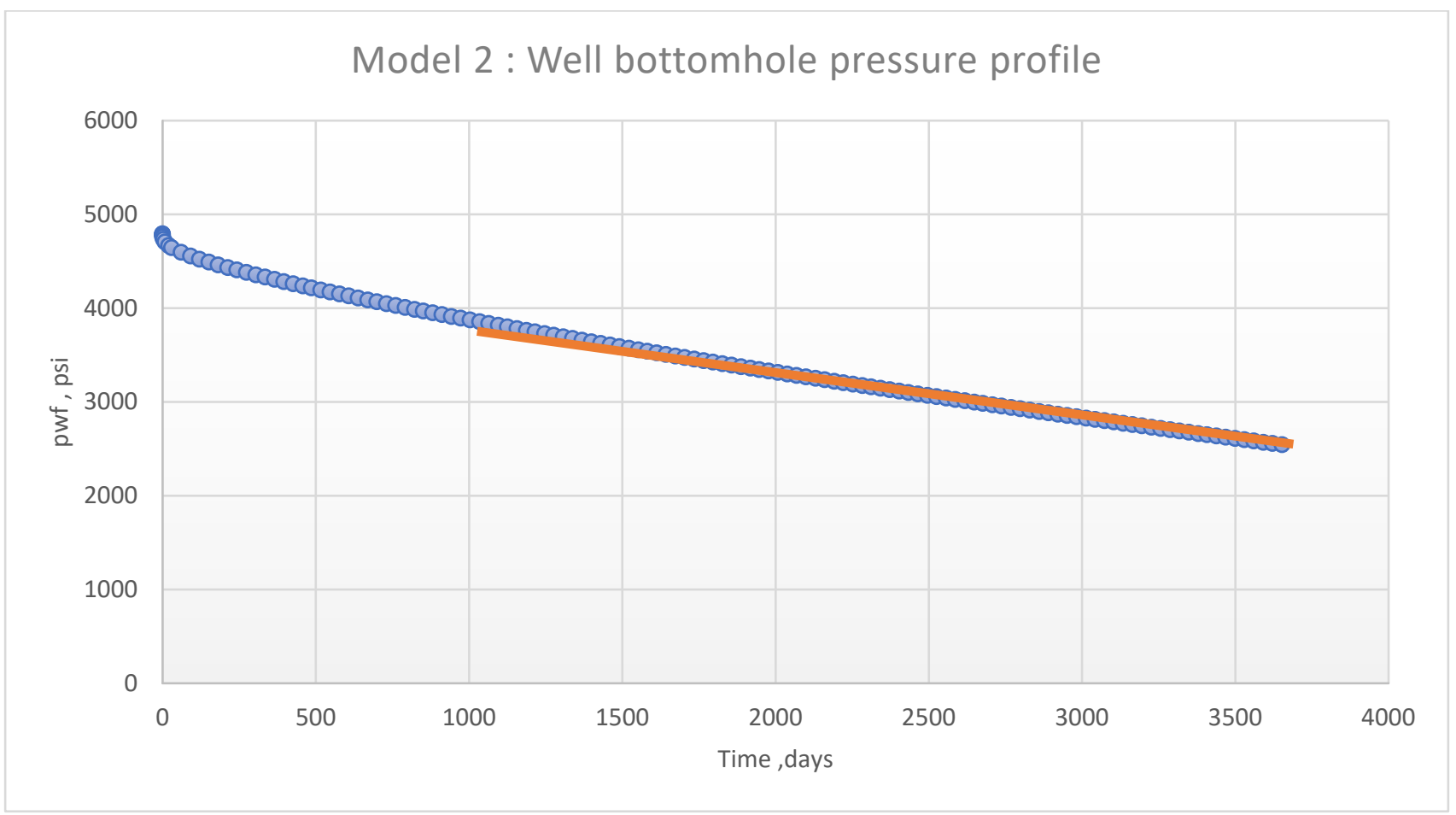

Figure 6: Well bottomhole Pressure Profile for Model 2 
Based on figure 6, The BDF period for the conventional and Clarkson-McGovern methods appears to be in the range of 1700-3600 days in real time which correspond to 1530-3000 days in pseudo time. The BDF period for the King's method appears to be from 2500-2600 days in real time which correspond to 2057-2140 in pseudo time.

Figure 7 illustrates that the FMB plot for Model 2. As it can be observed, one period of BDF(straightline trends) appears to be present. The gas in place was calculated based on the slope of the BDF. The estimated of gas in place based on the BDF turned out to be $4565 \mathrm{MMCF}$.

Figure 8 illustrates FMB plot based on the King's method for Model 2. Again, one period of the BDF appears to be present. The BDF resulted in a gas in place of $4782 \mathrm{MMCF}$.

Figure 9 illustrates FMB plot based on the Clarkson-McGovern method for Model 2. Again, one period of the BDF appears to be present.The BDF resulted in a gas in place of 4433 MMCF. Table 5 summarizes the Model 2 results for each case for comparison.

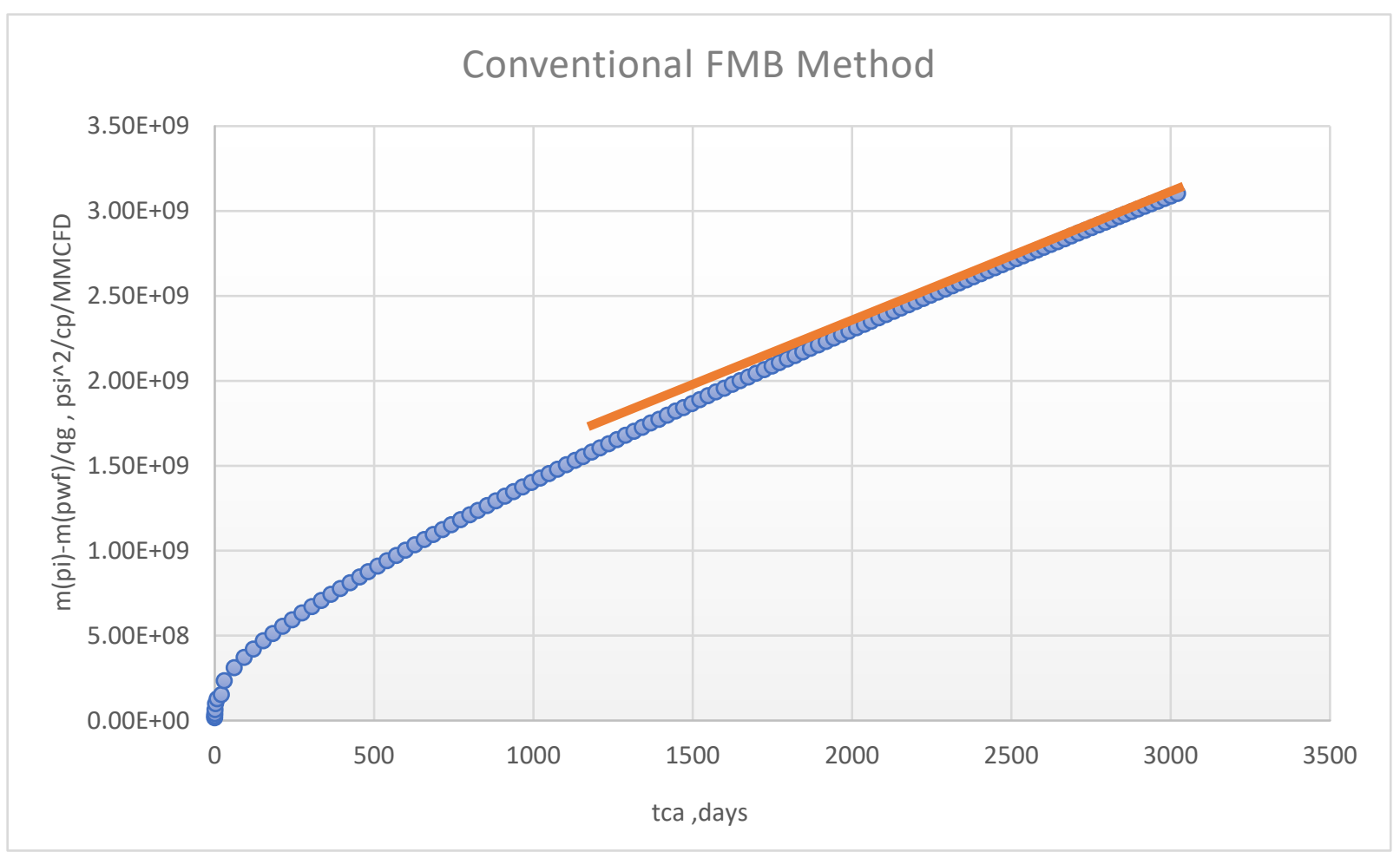

Figure 7: Conventional Flowing Material Balance Plot for Model 2 


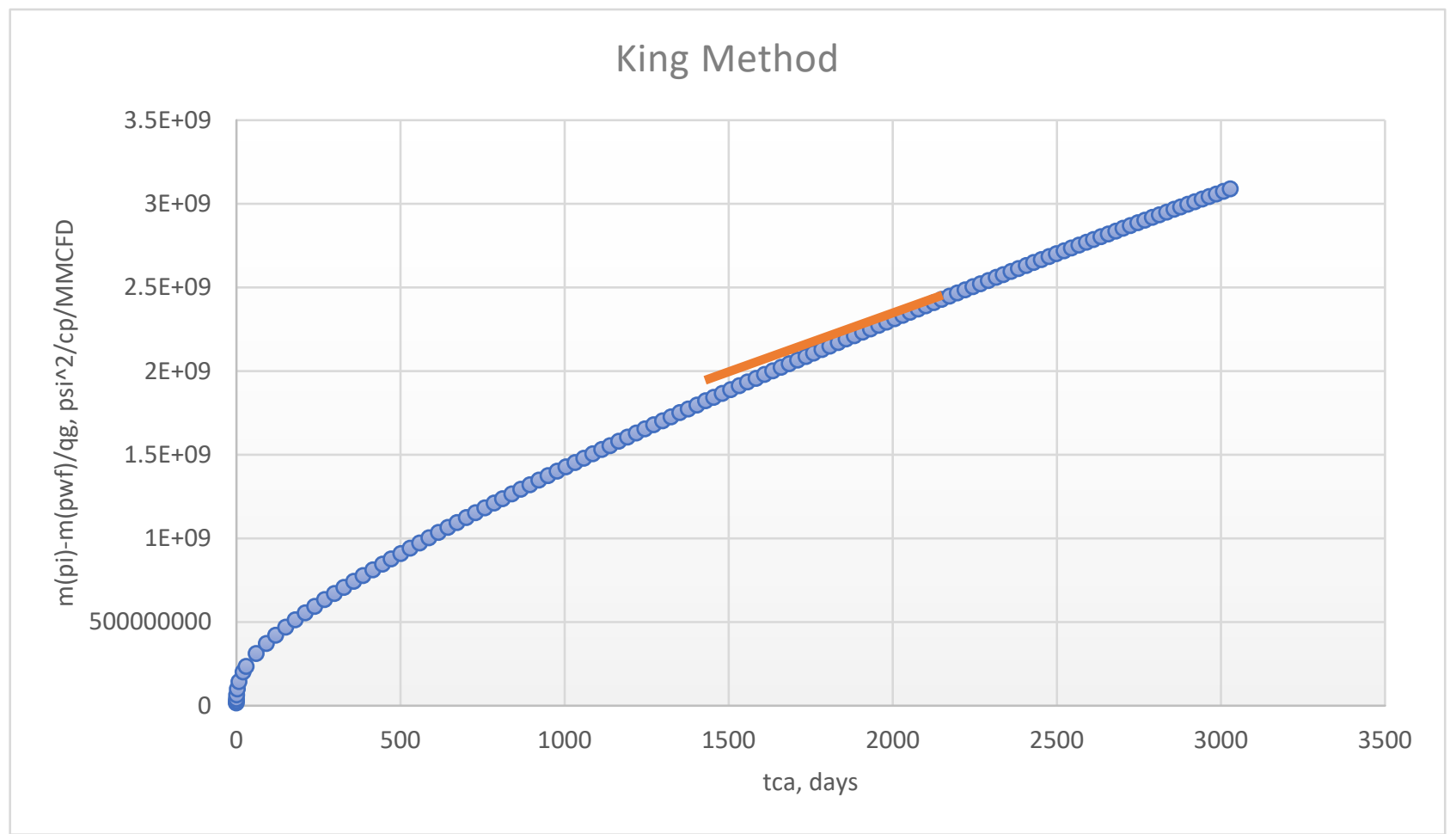

Figure 8: King Flowing Material Balance Plot for Model 2

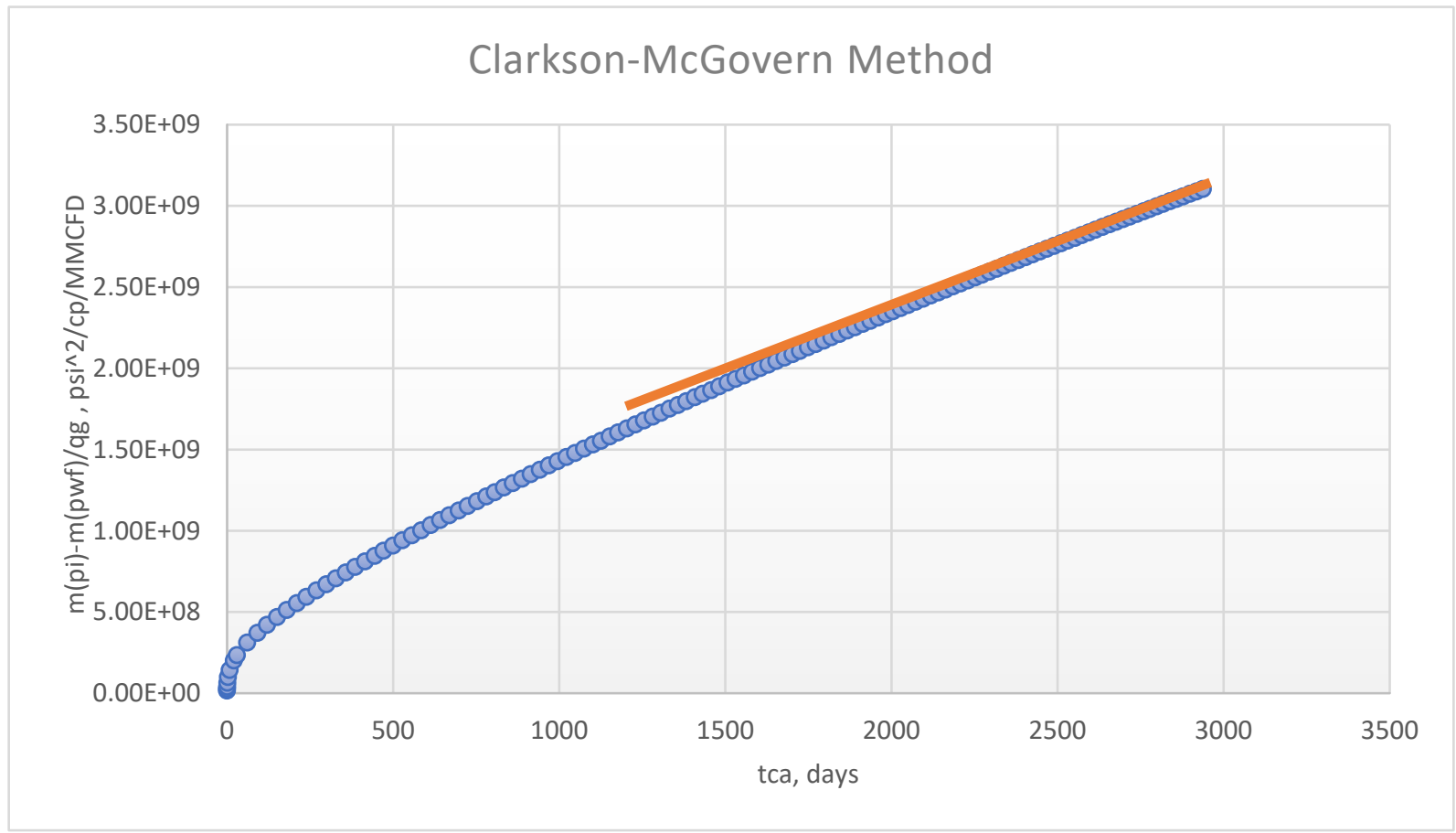

Figure 9: Clarkson-McGovern Flowing Material Balance Plot for Model 2 
Table 5: Comparison of the Results for Model 2

\begin{tabular}{|l|c|}
\hline Method & Gas in Place, MMCF \\
\hline CMG Model & 4304 \\
\hline Conventional FMB & 4565 \\
\hline King Method & 4782 \\
\hline Clarkson-McGovern Method & 4433 \\
\hline
\end{tabular}




\section{Chapter 5: Conclusion and Recommendations}

This conclusions were reached in this study

1. Two boundary dominated flow (BDF) periods may be present for a hydraulically fractured gas reservoir with ultra-low permeability (Model 1).

2. The early BDF may provide the estimate of the gas in place for the stimulated reservoir volume (SRV).

3. The late BDF can provide the estimate of the gas in place for the entire reservoir.

4. Clarkson-McGovern method provided the most accurate predictions of the gas in place, for both SRV and the total gas for Model 1.

5. Only one BDF period appears to be present for the low-permeability reservoir without hydraulic fracture (Model 2) which can be used to estimate the total gas in place.

6. Clarkson-McGovern method provided the most accurate prediction of the gas in place for the total gas in place for Model 2.

It is recommended that additional case (Models) to be considered to further investigate the impact of the number and properties of the hydraulic fractures, the gas adsorption parameters, and the formation properties on the application of FMB to ultra-low permeability reservoirs. 


\section{References}

Han, G., Liu, M., \& Li, Q. (2020). Flowing material balance method with adsorbed phase volumes for unconventional gas reservoirs. Energy Exploration \& Exploitation, 38(2), 519-532.

Moghadam, S., Jeje, O., \& Mattar, L. (2011). Advanced gas material balance in simplified format. Journal of Canadian Petroleum Technology, 50(01), 90-98.

Mattar, L., \& Anderson, D. (2005, January). Dynamic material balance (oil or gas-in-place without shutins). In Canadian International Petroleum Conference. Petroleum Society of Canada.

King, G. R. (1993). Material-balance techniques for coal-seam and devonian shale gas reservoirs with limited water influx. SPE Reservoir Engineering, 8(01), 67-72.

Clarkson, C.R. and McGovern, J.M. (2001) Study of the Potential Impact of Matrix Free Gas Storage Upon Coalbed Gas Reserves and Production Using a New Material Balance Equation. Paper 0113, Proceedings of the 2001 International Coalbed Methane Symposium, The University of Alabama, Tuscaloosa, Alabama, p. 133-149.

Williams-Kovacs, J.D., Clarkson, C.R., , Nobakht, M.,(2012), Impact of Material Balance Equation Selection on Rate-Transient Analysis of Shale Gas. SPE 158041

Morad , K., \& Clarkson, C. R. (2006). Application of Flowing P/z* Material Balance for Dry CoalbedMethane Reservoirs . Society of Petroleum Engineers .

Mattar, L., \& McNeil, R. (1998). The "Flowing" Gas Maerial Balance . Petroleum Society of Canada

Agarwal, R. G., Gardner, D. C., Kleinsteiber, S. W., \& Fussell, D. D. (1998). Analyzing Well Production Data Using Combined Type Curve and Decline Curve Analysis Concepts

El Sgher, M., Aminian, K., \& Ameri, S. (2019, October 15). The Impact of Rock Properties and Stress Shadowing on the Hydraulic Fracture Properties in Marcellus Shale. Society of Petroleum Engineers. doi:10.2118/196590-MS 